\title{
BMJ
}

\section{The impact of advance care planning on end of life care in elderly patients: randomised controlled trial}

\author{
Karen M Detering, respiratory physician and clinical leader, ${ }^{1}$ Andrew D Hancock, project officer, ${ }^{1}$ Michael C \\ Reade, physician, ${ }^{2}$ William Silvester, intensive care physician and director ${ }^{1}$
}

\begin{abstract}
${ }^{1}$ Respecting Patient Choices
Program, Austin Health,

PO Box 555, Heidelberg, Victoria, Australia 3084

2Intensive Care Unit, Austin Health Correspondence to: $\mathrm{K} M$ Detering Karen.detering@austin.org.au
\end{abstract}

Cite this as: BMJ 2010;340:c1345 doi:10.1136/bmj.c1345

\section{ABSTRACT}

Objective To investigate the impact of advance care planning on end of life care in elderly patients.

Design Prospective randomised controlled trial.

Setting Single centre study in a university hospital in Melbourne, Australia.

Participants 309 legally competent medical inpatients aged 80 or more and followed for six months or until death.

Interventions Participants were randomised to receive usual care or usual care plus facilitated advance care planning. Advance care planning aimed to assist patients to reflect on their goals, values, and beliefs; to consider future medical treatment preferences; to appoint a surrogate; and to document their wishes.

Main outcome measures The primary outcome was whether a patient's end of life wishes were known and respected. Other outcomes included patient and family satisfaction with hospital stay and levels of stress, anxiety, and depression in relatives of patients who died. Results 154 of the 309 patients were randomised to advance care planning, 125 (81\%) received advance care planning, and 108 (84\%) expressed wishes or appointed a surrogate, or both. Of the 56 patients who died by six months, end of life wishes were much more likely to be known and followed in the intervention group $(25 / 29$, $86 \%)$ compared with the control group $(8 / 27,30 \%$; $\mathrm{P}<0.001)$. In the intervention group, family members of patients who died had significantly less stress (intervention 5, control 15; P<0.001), anxiety (intervention 0 , control 3; $\mathrm{P}=0.02$ ), and depression (intervention 0 , control 5; $\mathrm{P}=0.002$ ) than those of the control patients. Patient and family satisfaction was higher in the intervention group.

Conclusions Advance care planning improves end of life care and patient and family satisfaction and reduces stress, anxiety, and depression in surviving relatives. Trial registration Australian New Zealand clinical trials registry ACTRN12608000539336.

\section{INTRODUCTION}

Since the 1990s there has been an increasing awareness of the inadequacy of end of life care and of the poor knowledge of patients' wishes about their medical treatment at a time when they lose the capacity to make decisions, ${ }^{1-3}$ resulting in patients being cared for in a way they would not have chosen. ${ }^{2}$ This has continued to the present day. ${ }^{4}$ Apart from progress in palliative care, the main focus to deal with these needs has been the development of advance care planning. Advance care planning is a process "whereby a patient, in consultation with health care providers, family members and important others, makes decisions about his or her future health care, should he or she become incapable of participating in medical treatment decisions." 5 The process of advance care planning informs and empowers patients to have a say about their current and future treatment. Advance care planning and the importance of improving end of life care are both supported by legislation in Australia, ${ }^{6}$ the United Kingdom, ${ }^{7}$ and the United States, ${ }^{89}$ and are endorsed by professional bodies, including the Australian, ${ }^{10}$ British, ${ }^{7}$ and American ${ }^{11}$ medical associations.

Elements of advance care planning include clarifying a patient's understanding of their illness and treatment options; understanding their values, beliefs, and goals of care; and identifying their wishes. If required a substitute decision maker (surrogate) is nominated. ${ }^{12} 13$ The potential barriers to advance care planning include the availability of trained staff with the time, competence, and confidence to discuss advance care planning with patients; organisational commitment and policy to support advance care planning; and ensuring that doctors understand and support advance care planning. ${ }^{14-16}$ Carrying out effective advance care planning in elderly patients is challenging, especially when they are acutely unwell and have a short length of stay in hospital before discharge.

Much of the focus on advance care planning has been on improving the completion rate of advance directives. ${ }^{1617}$ Such improvement does not necessarily improve medical care ${ }^{11618}$ or end of life care. ${ }^{119}$ Models of advance care planning such as the Respecting Choices programme have shown that a coordinated, systematic, patient centred approach to advance care planning by trained non-medical facilitators can improve outcomes for patients. ${ }^{1320-22}$ Evidence also shows that advance care planning and end of life discussions reduce stress, anxiety, and depression in surviving relatives. ${ }^{23-26}$ 


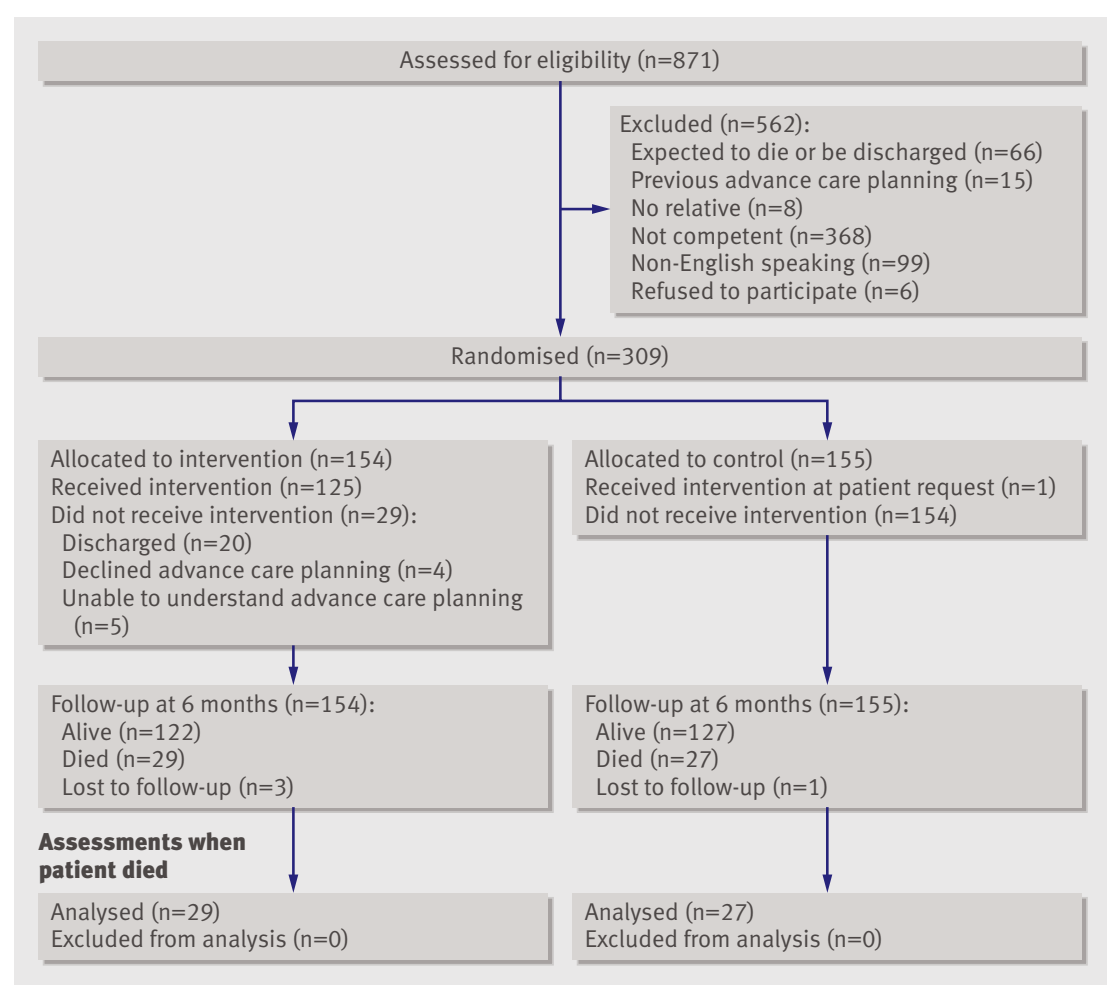

Patient allocation and evaluation assessment consisted of two components. Firstly, the patient's medical record was checked for exclusion criteria. KMD or WS then briefly interviewed potential participants to determine whether they were competent, as judged by their ability to understand and discuss illness, and their current and possible future treatment, and to identify an appropriate surrogate. After informed consent was obtained, patients were enrolled and asked to nominate a family member as an appropriate contact. The relative also provided informed consent. Non-research staff carried out the randomisation using sealed envelopes containing allocation cards assigned by random numbers. All analysis was done by intention to treat.

\section{Intervention}

Intervention patients received formal advance care planning from a trained facilitator (nurse or allied health worker) using the Respecting Patient Choices model $^{12}$ (see web extra on bmj.com). This programme, developed at the Austin Hospital in Melbourne, Australia, is based on the Respecting Choices programme $^{2128}$ and involves a coordinated approach to advance care planning whereby trained non-medical facilitators, in collaboration with treating doctors, assist patients and their families to reflect on the patient's goals, values, and beliefs, and to discuss and document their future choices about health care. Patients are encouraged to appoint a surrogate and to document their wishes about end of life care, including the wish for life prolonging treatments and cardiopulmonary resuscitation recorded on an advance care plan. As needed, treating doctors participated in this discussion to ensure that the patients understood their illness, treatment options, and likely prognosis. This programme utilises relevant legislation ${ }^{29}$ by enabling appointment of legal surrogates, and ensures a systematic approach to filing of completed documents in hospital medical records so that they are readily available.

Patients were encouraged to include their families, particularly their nominated surrogates, in discussions. The aim was to complete advance care planning before hospital discharge. Consistent with usual practice, control patients received usual medical care but no advance care planning, unless it was specifically requested.

\section{Study assessments}

Data collected at enrolment included age, sex, admission diagnosis, the existence of a form requesting no resuscitation, whether the patient had a surrogate, and whether the patient already had any wishes on end of life care, including life prolonging treatment or cardiopulmonary resuscitation. At or immediately after hospital discharge the patient or the family member (if the patient had died) completed a discharge questionnaire. Patients were also contacted by telephone at three and six months after enrolment. If the patient was unreachable, the family member was telephoned. If the patient had died within six months of study enrolment, the family member was interviewed at about three months after the date of death about the

\section{Study design}

One of the medical researchers (KMD, WS) assessed the patients on the third day of admission. The 
Table 1|Baseline characteristics and pre-existing wishes of patients. Values are numbers (percentages) unless stated otherwise

\begin{tabular}{lcc} 
Characteristics & $\begin{array}{c}\text { Intervention group } \\
(\mathbf{n}=154)\end{array}$ & $\begin{array}{c}\text { Control group } \\
(\mathbf{n}=155)\end{array}$ \\
Median (interquartile range) age (years) & $85(82-88)$ & $84(81-87)$ \\
\hline Men & $83(54)$ & $64(41)$ \\
\hline Main admission diagnosis: & $53(34)$ & $50(32)$ \\
\hline Cardiac & $50(33)$ & $47(30)$ \\
\hline Respiratory & $13(8)$ & $22(14)$ \\
\hline Falls & $38(25)$ & $36(24)$ \\
\hline Other & $26(17)$ & $32(21)$ \\
\hline Donot resuscitate form completed by medical team at admission & & $20(13)$ \\
\hline Surrogate* appointed before admission: & $18(12)$ & $133(86)$ \\
\hline Yes & $130(84)$ & $2(1)$ \\
\hline No & $6(4)$ & $80(52)$ \\
\hline Unknown & & $59(38)$ \\
\hline Would want cardiopulmonary resuscitationt: & $72(47)$ & $16(10)$ \\
\hline Yes & $58(38)$ & $122(79)$ \\
\hline No & $24(16)$ & $31(20)$ \\
\hline Don't know & $114(74)$ & $2(1)$ \\
\hline Would want life prolonging treatmentt: & $37(24)$ & \\
\hline Yes & $3(2)$ & \\
\hline No & & \\
\hline Don't know & & \\
\hline Surogate & & \\
\hline
\end{tabular}

*Surrogate decision maker.

†Patient's wishes, as collected by medical researchers during eligibility and enrolment interview before randomisation. quality of death and compliance with known end of life wishes. The family member also completed a quality of end of life care questionnaire, an impact of events scale $^{30}$ and the hospital anxiety and depression scale. ${ }^{31}$ The same researcher (KMD) administered the questionnaires in person or by telephone; she did not facilitate advance care planning and was unaware of patient allocation.

\section{Outcome measures}

The primary outcome measure was the proportion of patients who had died and whose end of life wishes were known and respected by their doctors. Compliance with wishes was determined by two researchers (KMD, WS), who reviewed the medical records of deceased patients and the quality of end of life care questionnaire to identify any documentation of the patient's wishes in the medical record, care received, compliance with the patient's wishes, and the impact of patient's wishes on medical decisions.

Secondary outcome measures included a five question survey of patient satisfaction on their hospital stay and an assessment of the impact of a patient's death on relatives, using the impact of events scale and hospital anxiety and depression scale. The impact of events scale is a validated 15 item tool that identifies the risk of developing post-traumatic stress disorder. ${ }^{30} 32$ The hospital anxiety and depression scale is a validated 14 item tool that measures symptoms of anxiety and depression. ${ }^{31}$ The quality of end of life care questionnaire is an eight item locally developed tool to assess a family member's satisfaction with the quality of a patient's death, from their own and perceived perspective of the deceased patient.

\section{Power calculation and statistical analysis}

On the basis of data collected in the preceding six months, we anticipated the baseline proportion of patients whose wishes were known and respected to be $15 \%$ and that an increase to $65 \%$ would represent a clinically meaningful effect. To achieve a $90 \%$ power to detect a difference in the primary outcome between groups with a certainty of $95 \%$ we estimated that 22 deaths would be required in each group. Our clinical database contained records of 900 patients aged 80 or more admitted to the relevant units over a period of six months in 2006, $63(7.0 \%)$ of whom died. We therefore calculated that to observe 44 deaths we would need to recruit 629 patients. Patient recruitment ended after seven months because of a higher than expected death rate in the recruited patients. No data were analysed before the study ended.

Statistical calculations were carried out using Stata version 9.2. We graphically assessed continuous data for normality and compared the data using $t$ tests or Mann-Whitney U tests. Categorical data were assessed using $\chi^{2}$ tests or Fisher exact tests. We report exact $\mathrm{P}$ values, with statistical significance defined as $\mathrm{P} \leq 0.05$.

\section{RESULTS}

Of 871 patients screened between August 2007 and March 2008, 309 (35.5\%) were enrolled: 154 were randomised to the intervention group and 155 to the control group. The figure shows the reasons for exclusion. The baseline characteristics between the groups were similar, including patients' wishes on life prolonging treatment as identified by the medical researchers during the eligibility and enrolment interview before randomisation (table 1).

\section{Intervention}

Advance care planning was delivered to 125 of 154 patients (81\%) assigned to the intervention group compared with 1 of 155 assigned to the control group $(0.6 \%)(\mathrm{P}<0.001$, figure)

Of the 125 patients who received advance care planning, $108(86 \%)$ expressed wishes on end of life care by completing an advance care plan $(\mathrm{n}=70,56 \%)$ or verbally. The facilitator recorded verbal wishes on an advance care planning discussion card $(n=38,30 \%$; table 2). The advance care planning facilitators reported that those patients who chose to have their verbally expressed wishes documented on the card felt just as strongly about their future wishes as those who completed an advance care plan. Of the 108 patients who expressed wishes on end of life care, 89 $(82 \%)$ expressed a wish about cardiopulmonary resuscitation and $81(75 \%)$ about life prolonging treatment. The remainder of the patients left the decisions to the surrogate, or were undecided.

The discussions on advance care planning lasted a median of 60 minutes (range 10-200 minutes) over 
Table 2 | Outcome of advance care planning in 125 patients who received intervention. Values are numbers (percentages) unless stated otherwise

\begin{tabular}{|c|c|c|c|c|c|}
\hline Outcomes & Not appropriate* & $\begin{array}{l}\text { Discussion, } \\
\text { no wishes } †\end{array}$ & $\begin{array}{l}\text { Discussion } \\
\text { card only } \ddagger\end{array}$ & $\begin{array}{l}\text { Documented advance } \\
\text { care plan§ }\end{array}$ & $P$ value \\
\hline Patients & $6(5)$ & $11(9)$ & $38(30)$ & $\begin{array}{l}\text { Total } 70 \text { (56); surrogate only, } 26 \text { (21); } \\
\text { end of life wishes only, } 14 \text { (11); both, } 30 \text { (24) }\end{array}$ & - \\
\hline Family present & $2(33)$ & $6(55)$ & $17(45)$ & $65(93)$ & $<0.001$ \\
\hline \multicolumn{6}{|l|}{ End of life wishes } \\
\hline \multicolumn{6}{|l|}{ Cardiopulmonary resuscitation: } \\
\hline Yes & NA & NA & $3(8)$ & $0(0)$ & - \\
\hline Yes, depending on outcomeף & NA & NA & $12(32)$ & $21(30)$ & - \\
\hline No & NA & NA & $14(36)$ & $39(56)$ & - \\
\hline Decided by doctor or surrogate & NA & NA & $9(24)$ & $10(14)$ & - \\
\hline \multicolumn{6}{|l|}{ Life prolonging treatment: } \\
\hline Yes & NA & NA & $3(8)$ & $0(0)$ & - \\
\hline Yes, depending on outcomeף & NA & NA & $12(32)$ & $27(39)$ & - \\
\hline No & NA & NA & $10(26)$ & $29(41)$ & - \\
\hline Decided by doctor or surrogate & NA & NA & $11(29)$ & $14(20)$ & - \\
\hline Undecided & NA & NA & $2(5)$ & $0(0)$ & - \\
\hline
\end{tabular}

*Facilitator decided to stop discussion because patient failed to grasp concept or refused further discussion.

†Advance care planning discussion held but patient elected not to appoint a surrogate or express any wishes.

$\ddagger$ Patient was clear about wishes but did not wish to complete an advance care plan. Wishes were documented by facilitator on an advance care planning discussion card filed in front of medical record.

$\S$ Legal appointment of surrogate or signed witnessed documentation of end of life wishes, or both, including cardiopulmonary resuscitation and life prolonging treatment.

TTreatment to be provided only if doctor anticipates good outcome.

one to three meetings with the patients and their family.

Advance care planning resulted in a threefold increase in the appointment of surrogates (18/154 before the intervention, 56/154 after the intervention, $\mathrm{P}<0.001$ ). Families were present in $72 \%$ of the discussions. The likelihood of achieving complete documentation for advance care planning correlated strongly with the presence of family members, including the surrogate $(\mathrm{P}<0.001$, table 2$)$.

\section{Primary outcome measure}

Six months after randomisation, end of life wishes were known and respected in 25 of $29(86 \%)$ patients who

\section{Box 1: Patients' responses on discharge questionnaire}

\section{Intervention group}

Outstanding staff

Very caring staff, no-one has asked me before what I would want when I get really sick. It was really great. It made me feel relieved

Everyone should have an opportunity to discuss these things

They asked me what I wanted and I told them and they listened ... wow they really cared

They were so interested in what I thought

Control group

It was very hard to get information on what was happening

The doctors didn't really listen

They all kept talking about me, but didn't let me have a say. It was like I wasn't important They made me think that I was too old, and a nuisance and in the way

They didn't speak to me and kept discussing everything with my family. I think they thought I was too old and couldn't understand died in the intervention group compared with only 8 of $27(30 \%)$ in the control group $(\mathrm{P}<0.001$, table 3$)$. Mortality at six months did not differ between the groups. Intervention patients $(17 / 23,74 \%)$ were more likely than control patients $(10 / 21,48 \%)$ to be involved in end of life decision making $(\mathrm{P}=0.02$; table 3$)$.

\section{Secondary outcome measures \\ Patient satisfaction}

Discharge questionnaires were completed by 272 $(88 \%)$ patients or family members (133 intervention, 139 control). Patients, or family members if patients died before discharge, in the intervention group were significantly more likely to be very satisfied in response to all questions $(\mathrm{P}<0.001$; table 4$)$. Twenty two of the 29 deaths in the intervention group were associated with positive comments compared with 5 of the 27 deaths in the control group $(\mathrm{P}<0.001)$. The corresponding values for negative comments were 3 and $15(\mathrm{P}<0.001)$; no comments were made in association with four patients in the intervention group and seven in the control group. Box 1 lists some of the patients' responses.

\section{Impact on family}

The family members of patients who died were interviewed a median of 104 days after the death, with no difference in timing of interviews between the intervention and control groups. Compared with the control group, the family members of patients who had died in the intervention group had fewer symptoms of posttraumatic stress, depression, and anxiety as measured on the impact of events scale (score $>30$ ) and the 
Table $3 \mid$ Outcomes in 56 patients who died. Values are numbers (percentages) unless stated otherwise

\begin{tabular}{|c|c|c|c|}
\hline Outcomes & Intervention group & Control group & $P$ value \\
\hline Patients & 29 (19) & $27(17)$ & 0.75 \\
\hline Median (interquartile range) age (years) & $85(84-89)$ & $84(81-87)$ & 0.06 \\
\hline Men & $17(59)$ & $13(48)$ & 0.43 \\
\hline Completed advance care planning & $25(86)^{\star}$ & $0(0)$ & $<0.001$ \\
\hline Wishes known and followed & $25(86)$ & $8(30)$ & $<0.001$ \\
\hline Wishes unknown & $3(10)$ & $17(63)$ & $<0.001$ \\
\hline Wishes known but not followed & $1(3)$ & $2(7)$ & 0.51 \\
\hline Location of death: & & & 0.09 (overall) \\
\hline Acute hospital but not intensive care unit & $16(55)$ & $12(44)$ & 0.42 \\
\hline Intensive care unit & $0(0)$ & $4(15)$ & 0.03 \\
\hline Home or non-acute hospital & $6(21)$ & $8(30)$ & 0.19 \\
\hline Palliative care & $7(24)$ & $3(11)$ & 0.20 \\
\hline \multicolumn{4}{|l|}{ End of life decision making: } \\
\hline None-died suddenly & $6(21)$ & $6(23)$ & \multirow{3}{*}{0.02} \\
\hline Involved in decision making & $17(58)$ & $10(37)$ & \\
\hline Not involved in decision making & $6(21)$ & $11(30)$ & \\
\hline \multicolumn{4}{|l|}{ Impact of events scale: } \\
\hline Median (interquartile range) score & $5(2-5.5)$ & $15(5-21)$ & $<0.001$ \\
\hline Score $>30 \dagger$ & $0(0)$ & $4(15)$ & 0.03 \\
\hline \multicolumn{4}{|l|}{ Hospital anxiety and depression scale: } \\
\hline Median (interquartile range) depression & $0(0-1.5)$ & $5(0-9)$ & $<0.001$ \\
\hline Score $>8 \ddagger$ & $0(0)$ & $8(30)$ & 0.002 \\
\hline Median (interquartile range) anxiety & $0(0-3.5)$ & $3(0-6)$ & 0.03 \\
\hline Score $>8 \ddagger$ & $0(0)$ & $5(19)$ & 0.02 \\
\hline \multicolumn{4}{|l|}{ Satisfaction with quality of death } \\
\hline \multicolumn{4}{|l|}{ Family member§ף: } \\
\hline Very satisfied & $24(83)$ & $13(48)$ & \multirow{3}{*}{0.02} \\
\hline Satisfied & $2(7)$ & $8(30)$ & \\
\hline Not satisfied & $3(10)$ & $6(22)$ & \\
\hline \multicolumn{4}{|c|}{ Family member's perception of patient's satisfaction**: } \\
\hline Very satisfied & $25(86)$ & $10(37)$ & \multirow{3}{*}{$<0.001$} \\
\hline Satisfied & $1(4)$ & $10(37)$ & \\
\hline Not satisfied & $3(10)$ & $7(26)$ & \\
\hline
\end{tabular}

*Discussion, no wishes $(n=3)$; advance care planning discussion card only $(n=8)$; documented advance care plan ( $n=14)$.

tHigh risk of developing post-traumatic stress disorder.

$\ddagger$ Clinically significant depression or anxiety.

$\S N o m i n a t e d$ by patient at enrolment to study.

IQuestion posed: How satisfied are you about the way in which $\mathrm{x}$ died?

${ }^{*}$ Question posed: Thinking about it from x's perspective, how satisfied are you that $\mathrm{x}$ died in the way that he/ she would have wanted to? relationships. ${ }^{33}$ Furthermore, although traditional understanding of the benefits of advance care planning are respect for autonomy, preparation for possible future incapacity, and completion of formal advance directives, patients see the benefits of advance care planning to include preparation for end of life care and death, avoidance of prolongation of dying, strengthening of personal relationships, relieving burdens placed on family, and the informal communication of future wishes. ${ }^{334}$

This randomised, controlled trial shows that advance care planning carried out properly by trained non-medical staff improves end of life care by enabling patients' wishes to be determined, documented, and respected at end of life. In this study, in the $92 \%$ of cases (33/36, table 3$)$ where wishes were known, they were respected. This is similar to the Respecting Choices programme ${ }^{20}$ but different to other studies that have assessed similar outcomes. ${ }^{119}$

Essential elements of the programme responsible for the primary outcome

We specifically focused on a model with five key elements identified by others as crucial to successful advance care planning ${ }^{162135}$ : trained facilitators, patient centred discussions, involvement of family in discussions, correctly filed documentation, and systematic education of doctors.

Patients welcome advance care planning and expect health professionals to initiate discussions. ${ }^{81936}$ Our trained facilitators provided advance care planning for $81 \%$ of intervention patients; only four patients refused to participate. By using non-medical (nursing and allied health) staff as advance care planning facilitators, like others ${ }^{172137}$ we made advance care planning more available and overcame the barrier of limited doctor time. Our findings dispel the common myth that patients are distressed by such discussion. Intervention patients were significantly more likely to be very satisfied with overall care in the hospital, the information provided, being listened to, and being involved in decision making (table 4). These findings on patient satisfaction, replicated elsewhere, ${ }^{26353638-40}$ are not surprising, given that this model of advance care planning is patient centred ${ }^{35}$ and encourages open discussion about patients' goals of care, "what it means to live well," ${ }^{41}$ and their values and beliefs.

Patients may also wish to document specific treatment preferences for cardiopulmonary resuscitation and prolongation of life. However, patients often poorly understand medical care ${ }^{19}$ including cardiopulmonary resuscitation, ${ }^{42}$ and may overestimate their probabilities of survival. ${ }^{3}$ Part of the focus during advance care planning is on realistic and achievable goals of care ${ }^{3}$ and improving the patient's understanding of their medical situation. Patients vary their choices when informed about the likelihood and severity of outcomes, including those related to functional and cognitive disability. ${ }^{434}$ Like others, ${ }^{151835}$ we found it more useful for patients to focus on goals for
End of life care requires improvement. ${ }^{1315}$ Patients considered five factors to be important for a "good death": managing symptoms, avoiding prolongation of dying, achieving a sense of control, relieving burdens placed on the family, and the strengthening of 


\begin{tabular}{|c|c|c|c|}
\hline Variables & $\begin{array}{l}\text { Intervention } \\
\text { group }(n=133)\end{array}$ & $\begin{array}{l}\text { Control group } \\
(n=139)\end{array}$ & Pvalue \\
\hline \multicolumn{4}{|c|}{ Overall level of satisfaction with hospital stay: } \\
\hline Very satisfied & $125(93)$ & $91(65)$ & \multirow{3}{*}{$<0.001$} \\
\hline Satisfied & $6(5)$ & $40(29)$ & \\
\hline Not satisfied & $2(2)$ & $8(6)$ & \\
\hline \multicolumn{4}{|c|}{ Satisfaction with information provided in hospital: } \\
\hline Very satisfied & $115(86)$ & $58(42)$ & \multirow{3}{*}{$<0.001$} \\
\hline Satisfied & $14(10)$ & $56(40)$ & \\
\hline Not satisfied & $4(4)$ & $25(18)$ & \\
\hline \multicolumn{4}{|c|}{ Satisfaction with being listened to in hospital: } \\
\hline Very satisfied & $127(94)$ & $72(52)$ & \multirow{3}{*}{$<0.001$} \\
\hline Satisfied & $4(4)$ & $47(34)$ & \\
\hline Not satisfied & $2(2)$ & $20(14)$ & \\
\hline \multicolumn{4}{|c|}{$\begin{array}{l}\text { Satisfaction with level of involvement in decisions } \\
\text { made in hospital: }\end{array}$} \\
\hline Very satisfied & $123(92)$ & $53(38)$ & \multirow{3}{*}{$<0.001$} \\
\hline Satisfied & $8(6)$ & $64(46)$ & \\
\hline Not satisfied & $2(2)$ & $22(16)$ & \\
\hline \multicolumn{4}{|c|}{$\begin{array}{l}\text { Satisfaction with level of family involvement in decisions } \\
\text { made in hospital: }\end{array}$} \\
\hline Very satisfied & $123(92)$ & $64(46)$ & \multirow{3}{*}{$<0.001$} \\
\hline Satisfied & $7(6)$ & $58(42)$ & \\
\hline Not satisfied & $3(2)$ & $17(12)$ & \\
\hline
\end{tabular}

care rather than on specific treatments for particular circumstances.

The third crucial element was to include the family in the discussion. Families were present in $72 \%$ of discussions on advance care planning. Family presence increased the likelihood that the patient would appoint a surrogate or complete an advance care plan, or both $(\mathrm{P}<0.001$, table 2). Appointing a surrogate is important ${ }^{1322343541}$ as it increases concordance between the wishes of a patient and the surrogate's knowledge of those wishes ${ }^{353945}$ and diminishes the sense of burden when end of life decisions are required.

The completion and correct, prominent filing of advance care planning documentation assists doctors to make decisions on end of life treatment. Documentation was completed in most of the discussions on advance care planning and was correctly filed in the medical records. Our findings are similar to those of a previous study, ${ }^{20}$ where $85 \%$ of decedents had advance directive documents and most were in the patients' records.

Education of doctors and other staff about the importance of advance care planning and end of life care is important, ${ }^{6121321}$ particularly in improving compliance with patients' wishes. ${ }^{46}$ The advance care planning facilitators involved the treating doctors in discussions on the patients' medical condition, possible treatments, and prognosis, as required, and also ensured medical staff were aware of any end of life wishes that patients expressed (verbally or in writing), especially if there was a wish to limit treatment. Only one patient in the intervention group and two in the control group had wishes that were known and not followed. This is a similar finding to others. ${ }^{20}$ Most patients who expressed an end of life care wish in this study did not want cardiopulmonary resuscitation or life prolonging treatment. Survival at six months was similar in both groups, which discounts the suggestion that advance care planning may be promoted as a mechanism to limit medical treatment. ${ }^{47}$

Four of these five key elements were absent from the SUPPORT study, a project that relied on a research nurse to relay information verbally to the treating doctor about a patient's preference for cardiopulmonary resuscitation, but which did not facilitate patient centred discussions, involve the patient's surrogate, and ensure that the treating doctor was aware of the patient's advance care plan when end of life decisions

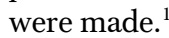

Legislation supports doctors following a patient's wishes, even if the patient wants to limit treatment. Although statutory law in Australia ${ }^{6}$ supports the legal appointment of surrogates, it is common law that recognises the right of competent adults to refuse medical treatment. ${ }^{48}$ Thus common law provides the main legal support for the ethical principle of patient autonomy and the concept of advance care planning.

\section{Other study outcomes}

Although overall the groups did not differ in site of death, the likelihood of dying in an intensive care unit differed significantly (none in intervention group, four in control group). The four control patients who died in the intensive care unit had multiple important pre-existing medical conditions, and each received many invasive procedures until shortly before death. It seems that in each of these cases, death was inevitable and, on review of the patient's files, there was evidence that some of the interventions received may have been unwanted. End of life decision making also differed significantly between the groups, with more patients involved in decision making in the intervention group (table 3). This is not surprising, given that these patients had time to reflect on their views and document their wishes and that they and their family felt more empowered to express a view on the medical treatment plan when required.

Emotional trauma was reduced in the family members of intervention patients who died. An impact of events scale score of more than 30 is associated with a high risk of developing post-traumatic stress disorder. ${ }^{2332}$ Scores of more than 8 on the hospital anxiety and depression scale subscales for depression and for anxiety are associated with clinically significant depression and anxiety. ${ }^{49}$ Scores of this level occurred only in the family members of control group patients who had died. Our programme involved surrogates throughout advance care planning, thereby increasing their knowledge and understanding of patients' wishes and reducing the burden of making difficult end of life decisions on behalf of patients. Advance care planning significantly reduced symptoms of post-traumatic stress, anxiety, and depression in family members. 
Box 2: Family members' responses on quality of end of life care questionnaire

\section{Intervention group}

His death was really peaceful, and everyone knew what to do

We had a clear plan so could just relax and enjoy time with dad

Even though we already knew what he wanted it was great to be given the opportunity to talk about it and get it out into the open

We felt really comfortable making decisions because we had discussed it with him

He had a very peaceful death, just as it should have been and I would like to thank all staff for this

\section{Control group}

He knew he was dying, and it was very hard for him. We should have talked with him about it

He should have had more say. He couldn't do the rehabilitation. He knew he was dying, but the doctors didn't seem to get it

The hospital has a responsibility to talk with patients about these things. My sister never got a say and that is wrong

They wouldn't let her go. They kept doing tests and things she would not have wanted

Mum didn't want heroics. She knew she was dying. I was horrified when I heard she got 45 minutes of CPR. She did not want it. All anyone had to do was ask. I feel very hurt and hurt for mum and my sister excluded patients aged less than 80 , the experience in our hospital is that advance care planning is successfully carried out in younger patients, with a higher proportion of patients competent to do so.

The questionnaire researcher was blinded to patient allocation, but the occasional responses of participants made patient allocation obvious. The researcher still recorded all questionnaire responses objectively, however, and this did not affect the primary outcome measure.

This was a single centre study of a complex inter vention, ${ }^{50}$ which will be potentially influenced by local cultural and systemic factors. However, despite this we believe that our model of advance care planning is likely to be generalisable to other healthcare settings. The Respecting Patient Choices model of advance care planning is derived from Respecting Choices, a programme that has been successfully implemented in multiple health services in the United States, as well as Canada, Germany, Spain, and Singapore. ${ }^{28}$ Furthermore, the Respecting Patient Choices programme has been implemented into health services in each Australian state and territory. ${ }^{12}$

We designed the study to follow all patients for six months after randomisation. It was not feasible to follow the surviving patients further as advance care planning was subsequently provided to the surviving control patients.

\section{Implications for clinicians and policy makers}

We believe our study highlights several factors that are important for both clinicians and policy makers. Firstly, the focus of advance care planning needs to be on improving communication between patients, their families, and doctors. Although documentation is often completed during the process of advance care planning, documentation alone is unlikely to improve outcomes. Secondly, advance care planning needs to be a coordinated approach involving the various members of the patient's treating health providers, including a trained advance care planning facilitator. Furthermore, advance care planning needs to become a part of usual care, and mechanisms need to be in place to ensure that it is offered to patients. Finally, successful advance care planning requires a change in systems to ensure that it occurs, the plans are readily available, and the care a person receives reflects their wishes. Health services need to develop policy around advance care planning and end of life care.

\section{Conclusions}

A coordinated, systematic model of patient centred advance care planning using non-medical advance care planning facilitators assists in identifying and respecting patient's wishes about end of life care, improves such care from the perspective of the patient and the family, and diminishes the likelihood of stress, anxiety, and depression in surviving relatives. 


\section{WHAT IS ALREADY KNOWN ON THIS TOPIC}

End of life care is poor and needs to be improved

Focusing on the completion of advance directives alone does not improve end of life care

Involving surrogates in discussions on advance care planning improves the likelihood that they will know the patient's end of life wishes

\section{WHAT THIS STUDY ADDS}

\section{Coordinated advance care planning improves end of life care}

Advance care planning reduces the incidence of anxiety, depression, and post-traumatic stress in surviving relatives

Advance care planning improves patient and family satisfaction with hospital care
14 Morrison RS, Morrison EW, Glickman DF. Physician reluctance to discuss advance directives. An empiric investigation of potential barriers. Arch Intern Med 1994;154:2311-8.

15 Winzelberg GS, Hanson LC, Tulsky JA. Beyond autonomy: diversifying end-of-life decision-making approaches to serve patients and families. J Am Geriatr Soc 2005;53:1046-50.

16 Prendergast TJ. Advance care planning: pitfalls, progress, promise. Crit Care Med 2001;29(2 suppl):N34-9.

17 Ramsaroop SD, Reid MC, Adelman RD. Completing an advance directive in the primary care setting: what do we need for success? Am Geriatr Soc 2007;55:277-83.

18 Tulsky JA. Beyond advance directives: importance of communication skills at the end of life. JAMA 2005;294:359-65.

19 Perkins HS. Controlling death: the false promise of advance directives. Ann Intern Med 2007;147:51-7.

20 Hammes BJ, Rooney BL. Death and end-of-life planning in one midwestern community. Arch Intern Med 1998;158:383-90.

21 Hammes BJ, Romer AL. The lessons from Respecting Your Choices: an interview with Bernard Hammes. Innovations in end-of-life care, 1999. www2.edc.org/lastacts/archives/archivesJan99/featureinn. asp.

22 Briggs L. Shifting the focus of advance care planning: using an indepth interview to build and strengthen relationships. J Palliat Med 2004;7:341-9. and interpreted the data, and drafted and revised the article. ADH conceived and designed the study and drafted and revised the article. MCR audited the data, did the statistical analysis, and critically revised the article. All authors gave final approval of the version to be published. KMD is the guarantor.

Funding: This study was carried out using staff employed in the Respecting Patient Choices programme, which receives public funding from the Australian Commonwealth and the Victorian state governments. No external funding was utilised.

Competing interests: All authors have completed the unified competing interest form at www.icmje.org/coi_disclosure.pdf (available on request from the corresponding author) and declare (1) no financial support for the submitted work from anyone other than their employer; (2) no financial relationships with commercial entities that might have an interest in the submitted work; (3) no spouses, partners, or children with relationships with commercial entities that might have an interest in the submitted work; and (4) no non-financial interests that may be relevant to the submitted work.

Ethical approval: This study was approved by the Austin hospital institutional research ethics committee. The trial proposal was submitted on 10 April 2007, some additional information was provided on 7 May 2007 , and approval was received on 31 July 2007 . See the web extra on bmj.com for the original submission.

Data sharing: No additional data available.

1 The Support Investigators. A controlled trial to improve care for seriously ill hospitalized patients. The study to understand prognoses and preferences for outcomes and risks of treatments (SUPPORT). JAMA 1995;274:1591-8

2 Winzelberg GS, Hanson LC, Tulsky JA. Beyond autonomy: diversifying end-of-life decision-making approaches to serve patients and families. J Am Geriatr Soc 2005;53:1046-50.

3 Singer PA, Martin DK, Kelner M. Quality end-of-life care: patients' perspectives. JAMA 1999;281:163-8.

4 Drazen JM, Desai NR, Green P. Fighting on. N Engl J Med 2009;360:444-5.

5 Singer PA, Robertson G, Roy DJ. Bioethics for clinicians: 6. Advance care planning. CMA/ 1996;155:1689-92.

6 Cartwright CM, Parker MH. Advance care planning and end of life decision making. Aust Fam Physician 2004;33:815-9.

7 British Medical Association. End-of-life decisions. BMA, 2007. www. bma.org.uk.

8 Emanuel LL, Barry MJ, Stoeckle JD, Ettelson LM, Emanuel EJ. Advance directives for medical care-a case for greater use. $N$ Engl J Med 1991;324:889-95

9 Gillick MR. Advance care planning. N Engl J Med 2004;350:7-8.

10 Australian Medical Association. AMA backs advance care planning by patients, 2006. www.ama.com.au/print/2429.

11 American Medical Association. Opinion 2.225: optimal use of orders-not-to-intervene and advance directives, 1998. www.amaassn.org/ama1/pub/upload/mm/Code_of_Med_Eth/opinion/ opinion2225.html.

12 Respecting Patient Choices Program. 2007. http://www. respectingpatientchoices.org.au/background/about-us.html.

13 Romer AL, Hammes BJ. Communication, trust, and making choices: advance care planning four years on. J Palliat Med 2004;7:335-40.
23 Azoulay E, Pochard F, Kentish-Barnes N, Chevret S, Aboab J, Adrie C et al. Risk of post-traumatic stress symptoms in family members of intensive care unit patients. Am J Respir Crit Care Med 2005;171:987-94.

24 Lautrette A, Darmon M, Megarbane B, Joly LM, Chevret S, Adrie C, et al. A communication strategy and brochure for relatives of patient dying in the ICU. N Engl J Med 2007;356:469-78.

25 Tilden VP, Tolle SW, Nelson CA, Fields J. Family decision-making to withdraw life-sustaining treatments from hospitalized patients. Nurs Res 2001;50:105-15.

26 Wright AA, Zhang B, Ray A, Mack JW, Trice E, Balboni T, et al. Associations between end-of-life discussions, patient mental health, medical care near death, and caregiver bereavement adjustment. IAMA 2008;300:1665-73.

27 Tolle SW, Tilden VP, Nelson CA, Dunn PM. A prospective study of the efficacy of the physician order form for life-sustaining treatment. J $A m$ Geriatr Soc 1998;46:1097-102.

28 Respecting Choices 2008. www.respectingchoices.org/.

29 Victorian Medical Treatment Act 1988. www.health.vic.gov.au/mta.

30 Horowitz M, Wilner N, Alvarez W. Impact of event scale: a measure of subjective stress. Psychosom Med 1979;41:209-18.

31 Zigmond AS, Snaith RP. The hospital anxiety and depression scale. Acta Psychiatr Scand 1983;67:361-70.

32 Sundin E, Horowitz M. Horowitz's impact of event scale evaluation of 20 years of use. Psychsom Med 2003 65:870-6.

33 Steinhauser KE, Clipp EC, McNeilly M, Christakis NA, McIntyre LM, Tulsky JA. In search of a good death: observations of patients, families, and providers. Ann Intern Med 2000;132:825-32.

34 Singer PA, Martin DK, Lavery JV, Thiel EC, Kelner M, Mendelssohn DC. Reconceptualizing advance care planning from the patient's perspective. Arch Intern Med 1998;158:879-84.

35 Briggs LA, Kirchhoff KT, Hammes BJ, Song M-K, Colvin ER. Patientcentered advance care planning in special patient populations: pilot study. J Prof Nurs 2004;20:47-58

36 Grimaldo DA, Wiener-Kronish JP, Jurson T, Shaughnessy TE, Curtis JR, Liu LL. A randomized, controlled trial of advanced care planning discussions during preoperative evaluations. Anesthesiology 2001;95:43-50; discussion 5A.

37 Pearlman RA, Starks H, Cain KC, Cole WG. Improvements in advance care planning in the Veterans Affairs System: results of a multifaceted intervention. Arch Intern Med 2005;165:667-74.

38 Tierney WM, Dexter PR, Gramelspacher GP, Perkins Al, Zhou XH, Wolinsky FD. The effect of discussions about advance directives on patients' satisfaction with primary care. J Gen Intern Med 2001;16:32-40.

39 Song M-K, Kirchhoff KT, Douglas J, Ward S, Hammes B. A randomized, controlled trial to improve advance care planning among patients undergoing cardiac surgery. Med Care 2005;43:1049-53.

40 Song M-K. Effects of end-of-life discussions on patients' affective outcomes. Nurs Outlook 2004;52:118-25.

41 Schwartz C, Lennes I, Hammes B, Lapham C, Bottner W, Ma Y. Honing an advance care planning intervention using qualitative analysis: the Living Well interview. J Palliat Med 2003;6:593-603.

42 Adams DH, Snedden DP. How misconceptions among elderly patients regarding survival outcomes of inpatient cardiopulmonary resuscitation affect do-not-resuscitate orders. J Am Osteopath Assoc 2006;106:402-4.

43 Volandes AE, Paasche-Orlow MK, Barry MJ, Gillick MR, Minaker KL, Chang Y, et al. Video decision support tool for advance care planning in dementia: randomised controlled trial. BMJ 2009;338:b2159. 
44 Fried TR, Bradley EH, Towle VR, Allore H. Understanding the treatmen preferences of seriously ill patients. N Engl J Med 2002;346:1061-6.

45 Schwartz CE, Wheeler HB, Hammes B, Basque N, Edmunds J, Reed G, et al. Early intervention in planning end-of-life care with ambulatory geriatric patients: results of a pilot trial. Arch Intern Med 2002;162:1611-8

46 Keay TJ, Alexander C, McNally K, Crusse E, Eger RE. Nursing home physician educational intervention improves end-of-life outcomes. $J$ Palliat Med 2003;6:205-13.

47 Levinsky NG. The purpose of advance medical planning-autonomy for patients or limitation of care? N Engl J Med 1996;335:741-3.
48 Skene L. Law and medical practice: rights, duties, claims and defences. 3rd ed. Australia: LexisNexisButterworths, 2008.

49 Pochard F, Azoulay E, Chevret S, Lemaire F, Hubert P, Canoui P, et al. Symptoms of anxiety and depression in family members of intensive care unit patients: ethical hypothesis regarding decision-making capacity.[see comment]. Crit Care Med 2001;29:1893-7.

50 Medical Research Council. Developing and evaluating complex interventions: new guidance. UK, 2008. www.mrc.ac.uk/ complexinterventionsguidance.

Accepted: 4 December 2009 